\title{
CIUDAD EN EXPLOSIÓN: transformaciones territoriales en la región metropolitana de la Sabana de Bogotá
}

\author{
Mauricio Romero Mejía \\ Universidad: Universidad Politécnica de Cataluña, Barcelona. \\ Director de la Tesis: Antonio Font Arellano. Co director: Julio Cesar Gómez Sandoval \\ mauromej@hotmail.com
}

\section{RESUMEN}

El trabajo tiene como objeto de estudio la morfogénesis de un sector de la Bogotá metropolitana compuesta por el sector norte de Bogotá y cuatro municipios próximos del norte del Distrito Capital. Describe e interpreta las transformaciones y cambios del espacio construido desde una aproximación morfológica, en su dimensión urbanística y arquitectónica. En el presente artículo se analizan los procesos de la morfogénesis desde mitad del siglo XX hasta el presente y se busca con ello explicar la forma de la urbanización del presente. El trabajo describe, analiza y clasifica el crecimiento metropolitano, su materialización y temporalidad.

Palabras clave: materialización, agregación, dispersión, polarización

\begin{abstract}
This work studies the morphogenesis of the northern sector of the Capital District of Bogotá, and four municipalities close to this sector. It describes and interprets the transformations and changes the built-up space from a morphological approach, in its urbanistic and architectonical dimension. The article analyzes the morphogenetic processes from the middle $20^{\text {th }}$ century to the present, and thus pretends to explain the way in which the area has been urbanized. The work describes, analyses and classifies Bogotá's metropolitan growth, its materialization and temporality.
\end{abstract}

Key words: materialization, aggregation, sprawl, polarization 


\section{EL PROCESO METROPOLITANO}

La conformación de una nueva ciudad metropolitana en la Sabana de Bogotá, a causa de la "explosión de la ciudad" (Font Arellano, 2007), es un proceso que se encuentra en marcha. La evidencia se observa en la urbanización reciente de las áreas rurales de la Sabana de Bogotá y en la materialización del proceso que tiene lugar en el territorio: la aparición en los últimos treinta años de ciertos patrones urbanísticos y arquitectónicos residenciales, productivos, de distribución y de ocio, junto a procesos informales de urbanización.

Una característica morfológica de la transformación de los territorios metropolitanos es la dispersión de la urbanización impulsada, entre otros muchos factores de primer orden, por la mejora en las infraestructuras del transporte vial y ferroviario, la mejora en las condiciones económicas del país y un mayor bienestar de las personas y la colmatación del núcleo de la ciudad central.

La urbanización de los últimos treinta años presenta diferencias profundas con el proceso que se había dado hasta finales de los años setenta. En Colombia, el crecimiento metropolitano se ha explicado fundamentalmente a partir de dos términos: "conurbación" y "suburbanización". Varios estudios desde los años noventa hasta el presente, con enfoques diversos, han aportado considerable conocimiento de la Sabana y su proceso de urbanización. Tanto estos estudios ${ }^{1}$ como los instrumentos de planificación y gestión (Planes de Ordenamiento, Planes Parciales, etc.) han englobado dentro de estos términos los diferentes procesos de la morfogénesis metropolitana (dispersión, polarización y extensión urbana), dejando de lado las particularidades y diferencias morfológicas del fenómeno del crecimiento metropolitano. El termino de suburbanización se ha usado para describir todo el fenómeno del crecimiento fuera de los núcleos urbanos, y así mismo, es figura jurídica expresada como una de las categorías de la clasificación del suelo que los planes de ordenamiento territorial tienen a su disposición. En el último trabajo sobre el área metropolitana de Bogotá, elaborado por la Secretaría Distrital de Planeación, se utiliza el término "consuburbanización" para definir el "continuum urbano" que ha producido la dispersión de la urbanización en la Sabana de Bogotá (Alcaldía Mayor de Bogota \& Ruiz, 2014)

En este artículo se analizarán y clasificarán los diferentes procesos de la morfogénesis metropolitana (modelos del crecimiento metropolitano) teniendo como criterio su implantación con respecto a la estructura espacial metropolitana y las relaciones que establecen con los núcleos urbanos, las aglomeraciones existentes, las infraestructuras de la movilidad y los elementos naturales. (Font Arellano, Llop, \& Vilanova, 1999, pág. 102)

Después de la gran expansión urbana de Bogotá en los años cincuenta, sesenta, y setenta, a finales de esta última década, las condiciones del crecimiento urbano de la región se transformaron. El núcleo urbano de Bogotá se hace ahora más continuo y compacto, y en la Sabana los núcleos urbanos del resto de los municipios más cercanos a Bogotá salen del inmovilismo urbano en el que habían permanecido hasta ese momento. Los fenómenos de expansión de los núcleos de los municipios ocurren posteriormente al de Bogotá: mientras en la ciudad esa expansión inicia en los años 50 y se prolonga intensamente en los 70, en los pueblos como Chía, Cajicá y Tocancipá el crecimiento se activa a partir de los años 70, aunque con importantes diferencias entre ellos. En Sopó ese proceso ocurre desde los años ochenta.

Simultáneamente a este proceso de expansión de los núcleos urbanos se identifican las primeras ocupaciones de la suburbanización residencial en los cerros de Chía, mediante la parcelación de propiedades rurales en lotes y la edificación de casas unifamiliares aisladas por encargo. En 1980 se inicia la urbanización de los cerros de Chía, con lo cual se inicia a gran escala el proceso de dispersión de la urbanización residencial, fenómeno que con el tiempo irá adquiriendo mucho más intensidad en el municipio y la región.

1 Bogotá-Sabana un territorio posible", es el primero de un conjunto de tres informes realizados por el CEDE de la Universidad de los Andes publicado en 1998. El segundo es "Directrices de Ordenamiento Territorial para Bogotá y la Región" realizado mediante un convenio entre el Departamento Administrativo de Planeación Distrital y CAF- CEDE 1 publicado en el año 2000 y el tercer informe se titula "Tendencias recientes de la ocupación territorial en Bogotá y la Región" realizado en un convenio Colciencias, Gobernación de Cundinamarca y el CEDE. Este conjunto de trabajos son un análisis del proceso de urbanización siendo los únicos en el conjunto de grandes estudios sobre el área metropolitana de Bogotá que tienen un enfoque desde el urbanismo. 
Desde los años noventa, la región metropolitana de Bogotá ha experimentado una intensa expansión urbana, especialmente los municipios metropolitanos más próximos a la ciudad central, en donde las tasas de crecimiento poblacional superaron las de Bogotá desde hace tres décadas. Aunque los núcleos urbanos tradicionales han crecido en magnitudes importantes, gran parte del crecimiento urbano se está dando por fuera de las áreas urbanas sobre el suelo rural. Ahí existe un fenómeno muy dinámico de dispersión de la urbanización que está transformando el paisaje rural sabanero tradicional, configurando territorios híbridos en los que nuevas condiciones urbanas se conjugan con las áreas rurales y en donde, al parecer, emerge alguna forma de ciudad territorial de reciente aparición en el contexto colombiano. (Sieverts, 2003)

\section{METODOLOGÍA}

Este trabajo está inscrito en la línea de investigación de Análisis y Proyecto Territorial del Departamento de Urbanismo y Ordenación del Territorio (DUOT). Tiene un enfoque empírico, con motivaciones prácticas, es decir, tiende al conocimiento y análisis de fenómenos directamente observables con el fin de dilucidar ciertas líneas proyectuales (Secchi, 1968) sobre el territorio.

El ámbito de estudio es la Sabana de Bogotá. Para su reconocimiento se ha construido un atlas inicial a nivel de toda el área metropolitana que permite identificar las zonas en donde el proceso de distribución espacial de los asentamientos de la residencia y de las actividades productivas metropolitana es más intenso. Se han seleccionado áreas específicas en donde las transformaciones territoriales, por medio de patrones urbanísticos de aparición recientes y la complejización del territorio, se han dado con mayor vigor.

Para el análisis territorial se han definido tres variables: la temporalidad, la distribución espacial o el orden territorial, y la lectura e interpretación morfo tipológica de la urbanización. Al ser superpuestas entre sí permiten cuantificar los procesos, identificar tendencias de localización de actividades y reconocer las variaciones de la forma metropolitana y su consiguiente formalización urbanística y arquitectónica.

La primera variable se refiere a la fase temporal del proceso de urbanización. Se han identificado la aparición de las edificaciones por los años disponibles de las aerofotografías y clasificados en los períodos de tiempo definidos para el análisis. Ello permite reconocer las lógicas de distribución de las ocupaciones según los períodos de análisis, y así comparar los momentos de la urbanización para encontrar diferencias, similitudes, intensidades y características propias del proceso, así como sus relaciones con el ciclo económico que determina la urbanización. El análisis multitemporal permite observar y cuantificar las variaciones en el tamaño de los núcleos urbanos tradicionales, así como la de los asentamientos dispersos que se localizan fuera de ellos.

La segunda variable se refiere a lo que Bernardo Secchi llama el "orden territorial" que significa "la distribución, sobre el territorio de que se trate, de los asentamientos destinados a residencias y actividades productivas y su utilización por diversos agentes". Se han identificado las actividades que más han aportado a la transformación del territorio en términos espaciales y económicos. Se han identificado seis diferentes actividades que se formalizan en diferentes patrones urbanísticos.

El estudio de la forma del espacio construido es la tercera variable, y se realiza desde una aproximación físico espacial, es decir, urbanística y arquitectónica. Esta dimensión del análisis nos permite identificar en el tiempo las variaciones de la forma metropolitana y su relación con los modelos de crecimiento metropolitano. Para analizar la dinámica del crecimiento metropolitano, se ha tomado la metodología (o teoría) desarrollada por profesores del DUOT para la interpretación del crecimiento metropolitano de Barcelona publicado en el libro La construcció del territori metropolitá: la morfogènesi de la regió urbana de Barcelona como herramienta para interpretar el proceso del crecimiento metropolitano de la Sabana de Bogotá. De allí se toman los criterios para definir estos modelos y su taxonomía, adaptándola a las condiciones específicas de la Sabana.

La cartografía ha sido herramienta esencial para la observación, interpretación, análisis y síntesis del trabajo. Se ha partido de una diversidad de bases cartográficas y se ha construido un mosaico de fotografías aéreas de diferentes años para realizar un trabajo de mapeo de la ocupación actual, así como de sus cambios en el tiempo y la distribución de actividades. Información que, antes de esta investigación era inexistente. La cartografía ha revelado aspectos como dimensiones de los patrones urbanísticos estudiados, configuraciones espaciales, relaciones con la infraestructura verde, la de movilidad y los núcleos urbanos. Así mismo, su interpretación muestra cómo, dentro de sus lógicas, ciertos patrones similares tienden a aglomerarse y a configurar «topologías» 
que revelan las transformaciones del territorio y el nacimiento de nuevas condiciones y configuraciones metropolitanas.

\subsection{El ámbito territorial}
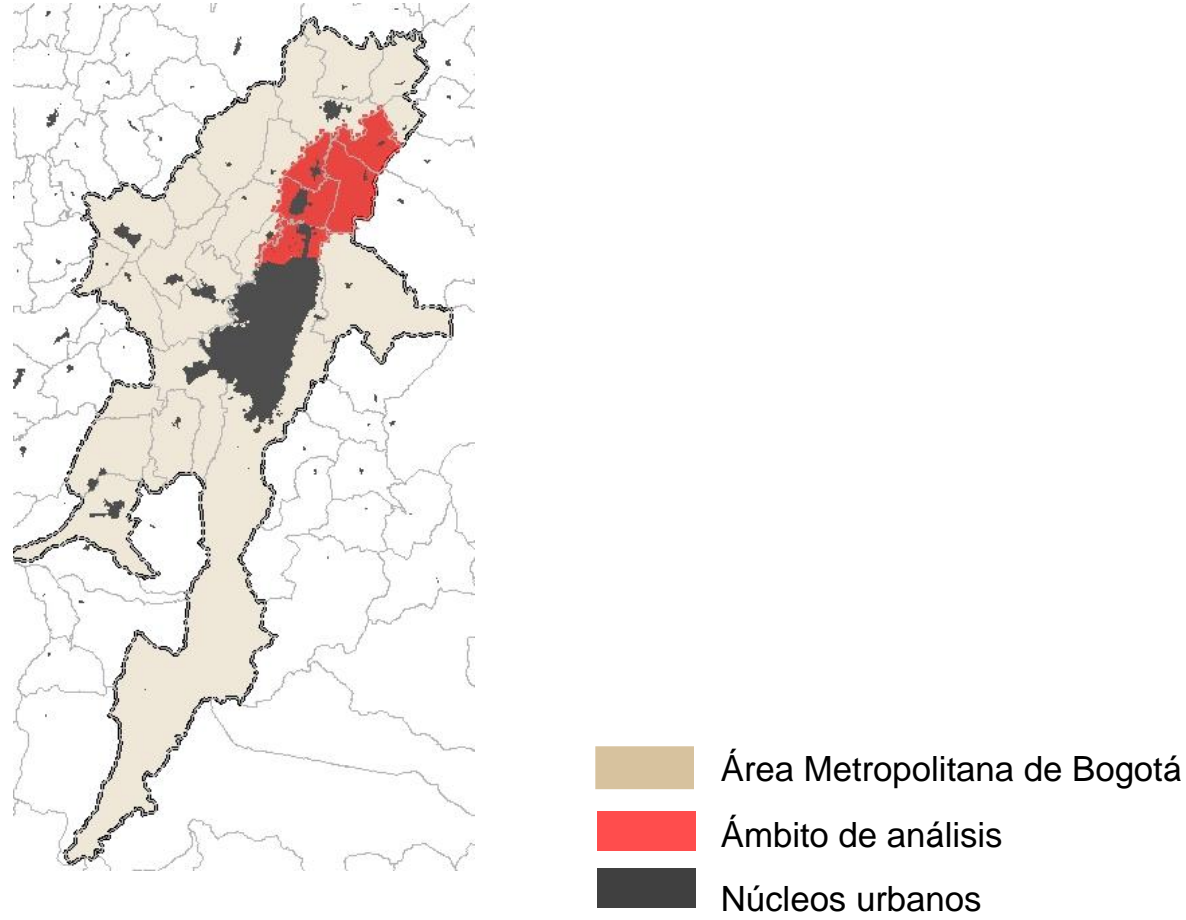

Imagen 1 Localización. Fuente: Elaboración propia con datos de POT Bogotá

El ámbito general de estudio es la región metropolitana de la Sabana de Bogotá. Como ámbito específico se identificaron las aéreas en donde la dinámica de ocupación, localización y variedad de actividades transformadoras del territorio son más intensas por cuenta de las relaciones de metropolización que Bogotá, en su proceso de expansión, ha establecido con los municipios de la Sabana. La investigación se concentra en el sector norte ${ }^{2}$ de Bogotá y los municipios de Chía, Cajicá, Sopo y Tocancipá, en el primer y segundo anillo de municipios de "borde urbano" del Distrito que, por los beneficios derivados de su localización relativa y de cercanía con el Distrito "han estimulado la demanda de urbanización de los suelos". (Alcaldía Mayor de Bogota \& Ruiz, 2014)

El proceso de urbanización de cada uno de estos municipios tiene particularidades que los distingue entre sí en varios aspectos.

La temporalidad del proceso: la metropolización de la Sabana de Bogotá se ha dado entre los años sesenta y el presente. En un lapso de cincuenta años la Sabana de Bogotá ha experimentado el fenómeno de urbanización más intenso de su historia. En este breve período de tiempo, las transformaciones territoriales en los municipios se han presentado en momentos diferentes y comprenden desde los inicios de la suburbanización en Chía en los setenta hasta la explosión del fenómeno que ha tenido lugar desde principios del siglo XXI hasta la actualidad.

Especialización funcional: estos municipios han configurado su vocación funcional en el sistema metropolitano. Chía y Cajicá son municipios con una vocación residencial de baja densidad, Sopó ha mantenido cierta vocación rural a pesar de la localización de grandes condominios residenciales y áreas industriales, y Tocancipá se caracteriza por el carácter industrial y logístico que ha adquirido desde los años noventa (Barco \& Cortés, 2000) que se intensifica especialmente a partir del año 2005.

${ }^{2}$ El sector que comúnmente se conoce como "Borde Norte". 
Particularidades morfológicas de la urbanización: La especialización de los municipios en ciertas actividades se proyectan en los patrones urbanísticos de aparición relativamente reciente y definen la morfología del espacio construido.

El papel de los núcleos urbanos tradicionales en el proceso de urbanización: Los núcleos urbanos municipales tienen características diferentes en los cinco municipios estudiados. En Chía y Cajicá los núcleos han sido aglutinadores (junto con proceso extensos de dispersión residencial) del crecimiento urbano en mayor medida que en Sopó y Tocancipá, en donde ha ocurrido un proceso de polarización intensa de la urbanización sobre las vías regionales exenta de los núcleos urbanos.

\subsection{Los períodos de análisis: el contexto político y económico}

La temporalidad analizada para identificar etapas del crecimiento metropolitano comienza con la expedición del Decreto 3654 de 1954 que incorporó cinco municipios de la región de la Sabana de Bogotá al municipio de Bogotá (Cortez, 2006). Este hecho marcó una ampliación del ámbito de planificación de la ciudad a una escala metropolitana, creando una entidad única municipal compuesta por seis antiguos municipios que gozaban de autonomía administrativa.

Las etapas posteriores se proponen teniendo en cuenta dos criterios: el primero relacionado con hechos de las esferas económicas y políticas a nivel nacional e internacional que tienen la capacidad de afectar el proceso urbanizador, y que pudieron tener alguna incidencia en el crecimiento metropolitano de Bogotá y la Sabana. El segundo criterio está formulado en relación con la disponibilidad de información, la cual cuenta con tres fuentes principales. En primer lugar, la información aerofotográfica, herramienta de observación fundamental de la realidad urbana en diferentes tiempos, nos permite identificar la evolución de la ocupación física del territorio metropolitano, tanto de los núcleos urbanos como de la ocupación más dispersa fuera de ellos, así como la construcción y transformación de las infraestructuras de la movilidad y la modificación del paisaje natural.

Los períodos de estudio son los siguientes: el primero inicia en el año de 1954 por cuanto la incorporación de los seis municipios a Bogotá significa el primer salto de la ciudad al ámbito metropolitano, la primera metropolización. Comprende hasta el año 1975, ya que la década de los años cincuenta y sesenta fue el momento de una expansión demográfica y urbanización del país muy importante.

El segundo período va de 1975 hasta 1991. El gran flujo migratorio masivo del campo a la ciudad va disminuyendo a partir de mediados de los años setenta (Gouset, 1998). Bogotá ha tenido una expansión urbana gigantesca en las décadas anteriores. El proceso de metropolización hacia el norte de Bogotá es más dinámico, materializándose en la dispersión incipiente de la urbanización residencial y la localización de algunos artefactos novedosos ${ }^{3}$ en el territorio sabanero. El año de 1991 es un hito especial a nivel político en Colombia por la elección de la Asamblea Nacional Constituyente que redactó una constitución más liberal que promulgó un Estado más descentralizado, introdujo reformas económicas que liberalizaron la economía y entregó a los entes municipales una mayor autonomía en todos los sentidos.

Entre 1992 a 2002, un período de tiempo de veinte años, corresponde al tercer período de análisis. Durante el gobierno de Cesar Gaviria (1990-1994) se profundizaron y aceleraron las reformas económicas de liberalización de la economía que se venían aplicando. Movilizaron la inversión privada hacia las obras de infraestructura, se privatizaron empresas y servicios que antes estaban en manos del Estado, y que fue una tendencia que se mantendría por las siguientes dos décadas. Al final de la década de los noventa, Colombia sufre la peor crisis económica y de orden público de los últimos años, y que afectó los procesos de urbanización y del mercado inmobiliario. (Ruiz, 2016)

\footnotetext{
${ }^{3}$ Contenedores comerciales, centros logísticos, parques industriales etc.
} 


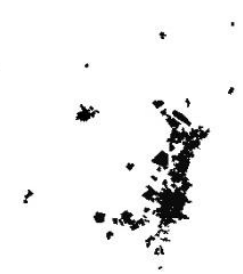

1938
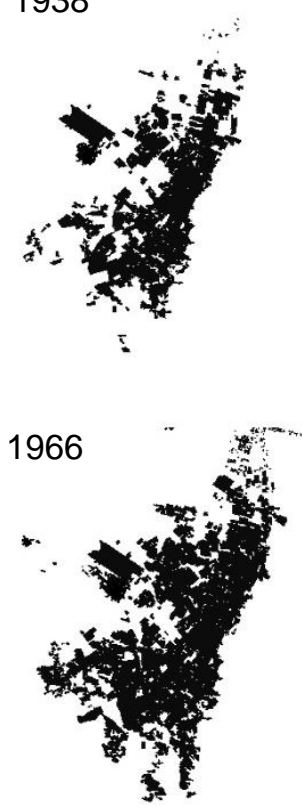

1984

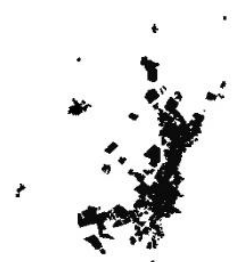

1949

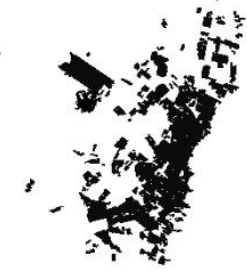

1960
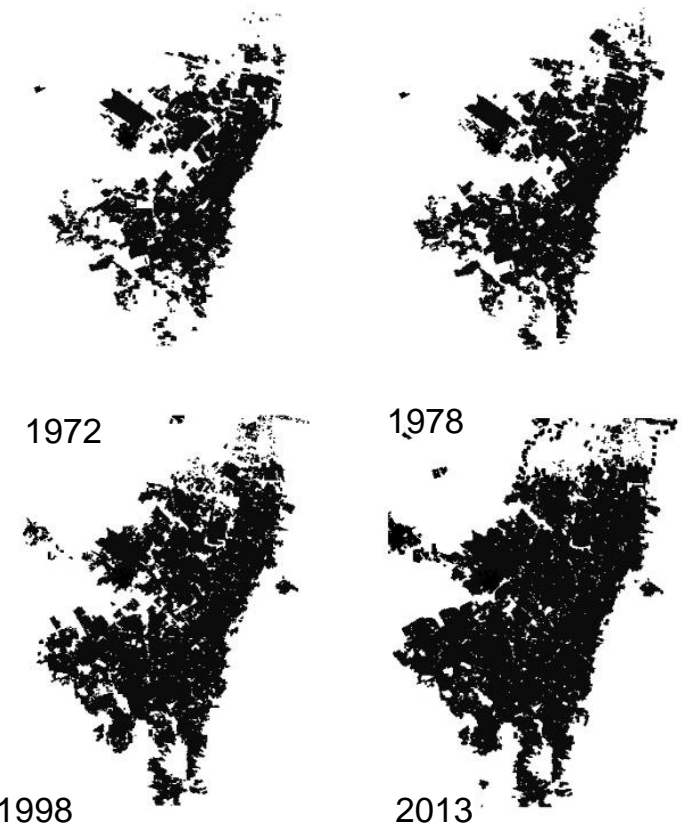

Imagen 2 Crecimiento del núcleo urbano de Bogotá. fuente: Elaboración propia en base a datos de Por Bogotá, Museo de Bogotá y UECD

El final del siglo tiene dos hechos fundamentales: una crisis económica importante y el desplazamiento interno de población junto al proceso de migración de colombianos al extranjero, tanto por la crisis económica como por el conflicto armado interno. El país se sobre-endeudó sumado a un desajuste macroeconómico importante y a la crisis del mercado hipotecario (alta inflación, tasa de cambio, exceso de liquidez). (Ruiz, 2016)

Esta situación tuvo como efectos en la economía una crisis de confianza y el aumento del desempleo que, desde 1996 subió a una tasa de dos dígitos llegando al pico máximo en el año 2000 con el $20.5 \% .{ }^{4}$ En un país con el panorama económico, político-social y de seguridad ensombrecido inicia el cuarto y último período que comprende desde el 2003 hasta el año 2016. En estos años se han profundizado las reformas económicas que liberalizaron la economía en Colombia y hacia el exterior. El país logra un nivel de armonización macroeconómica, se libera el mercado cambiario, hay un mayor control fiscal, baja la inflación y se promueve la atracción de capital extranjero.

La expresión física en el proceso de urbanización, en el caso metropolitano de Bogotá, podría ser que se impulsa el crecimiento industrial y logístico, el cual demanda una cantidad de suelo que es suplido en gran parte por los municipios metropolitanos más próximos a Bogotá. Hay un proceso inicial de relocalización y nueva industria que

4 Tomado Banco de la República. Tasas de empleo y desempleo para Siete áreas metropolitanas. https://www.banrep.gov.co/es/tasasempleo-desempleo 

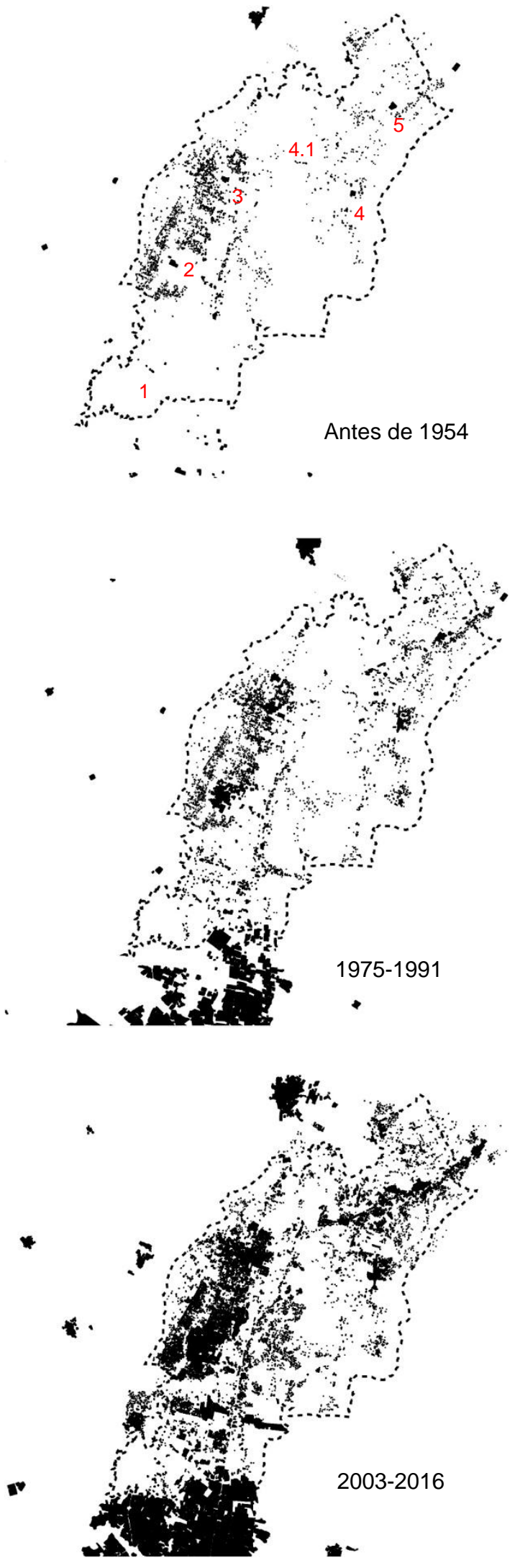

1. Bogotá D. C

2. Chía

3. Cajicá

4. Sopó

4.1. Briceño

5. Tocancipá

Imagen 3 Crecimiento urbano del ámbito de análisis por periodos. Fuente: elaboración propia con base en datos del IGAC, UECD, POT Chía, POT Cajicá, (Calderon, 2016), Google Earth. 
sirve como atractor de población y otras actividades a los municipios, lo que dinamiza el mercado inmobiliario en Bogotá y su área metropolitana (Ruiz, 2016). En el panorama político y en lo referente al conflicto armado existe una continuidad de la crisis en los primeros años de la década del 2000, y se encuentra en plena implementación el Plan Colombia que atrajo una cantidad de fondos muy importantes para la estrategia de seguridad y defensa. Simultáneamente, las cifras de desplazamiento forzado aumentaron entre el año 1997 y 2004 , lo que se conoce como el "gran éxodo forzado en la Colombia contemporánea" y, entre el año 2005 y el 2014, el informe Nacional del Desplazamiento Forzado en Colombia lo define como "persistencia del desplazamiento en escenarios de búsqueda de la paz. (Centro Nacional de Memoria Histórica, 2015)

En el contexto económico, el país ha tenido una bonanza energética por cuenta de los altos precios internacionales del petróleo y las materias primas que llegó a su fin entre los años 2014 y 2015.

\section{LOS PROCESOS DE LA MORFOGÉNESIS: los modelos de crecimiento metropolitano}

Una de las hipótesis de este trabajo parte de que las lógicas del crecimiento metropolitano en la Sabana de Bogotá se explican mediante la identificación de tres modelos de crecimiento metropolitano que han tenido lugar simultáneamente, pero cada uno de ellos tiene énfasis en momentos específicos caracterizados por condiciones socio económicas, políticas y culturales determinadas.

La materialización de estos modelos —crecimiento por agregación, crecimiento por dispersión, crecimiento por polarización (que incluye el crecimiento insular) (Font Arellano, Llop, \& Vilanova, 1999) — se expresa en patrones urbanísticos específicos que aparecen, cambian y/o se acentúan en períodos de tiempo determinados pero que tienen cierta simultaneidad, especialmente en los últimos treinta años cuando la urbanización del territorio sabanero ha sido especialmente intensa.

El hecho de que alguno de estos modelos de crecimiento metropolitano tenga un mayor acento en determinado momento no quiere decir que alguno de los otros modelos necesariamente desaparezca o que el fenómeno de la urbanización presente los modelos secuencialmente.

\subsection{La materialización de los procesos}

Los patrones urbanísticos son la estructura espacial, urbanística, arquitectónica y funcional mediante los cuales el crecimiento metropolitano adquiere su materialidad. Se han identificado seis grandes actividades: residenciales, productivos, comerciales, dotacionales, metabólicos y del ocio, que se materializan en diversos patrones urbanísticos que se definen en función de su morfología 5 . Se identificaron los patrones que son los mayores transformadores del territorio rural metropolitano y que han cambiado la percepción, tanto de la ciudad como del campo metropolitano. Son el ejemplo del fenómeno de la urbanización del campo mediante la extensión de actividades urbanas, más allá de los núcleos tradicionales, diseminadas por el territorio que nos sugiere la emergencia de un concepto de aglomeración urbana transformada (Sieverts, 2003).

El patrón urbanístico se refiere a la configuración física concreta, es decir, al sistema de relaciones entre parcelas, edificios, vialidad, espacio libre, equipamientos y dotaciones, que son las nuevas modalidades de organización espacial que construyen la realidad metropolitana reciente. Un ejemplo de ellos son los patrones urbanísticos de las actividades económicas. ${ }^{6}$ En una de sus categorías, los parques logísticos, por ejemplo, interesa conocer sus lógicas de implantación, su organización espacial, las actividades que se desarrollan en su interior, las relaciones que establece con los núcleos urbanos, con el espacio público, con las grandes vías de comunicación, entre otras. El patrón se refiere a la "esencia" de ese sistema. En el caso de una instalación logística, está organizada para que unos grandes camiones o tráileres lleguen a unos artefactos organizadas para que, por un costado, unos diques permitan iniciar la labor de descarga de mercancías que será recibida por el otro costado por unas furgonetas que trasladarán la carga, iniciando así un proceso de distribución a menor escala. La tipología está

5 Siete patrones residenciales, cuatro patrones productivos, cinco comerciales, tres dotacionales, tres metabólicos y cinco patrones del ocio.

6 Parques Industriales, Centros logísticos, factorías asiladas, centros direccionales etc. 
dada en función del tipo de uso y actividad materializada en una configuración típica que le permite llevar a cabo determinada actividad. Por lo tanto hay condiciones que se repiten en todos los parques logísticos sin que esta característica repetitiva, tipológica, los haga iguales (Font A. , 2014).

"Cada patrón describe un problema que ocurre una y otra vez en nuestro entorno, para describir después el núcleo de la solución a ese problema, de tal manera que esa solución pueda ser usada más de un millón de veces sin hacerlo ni siquiera dos veces de la misma forma" (Alexander, 1977).

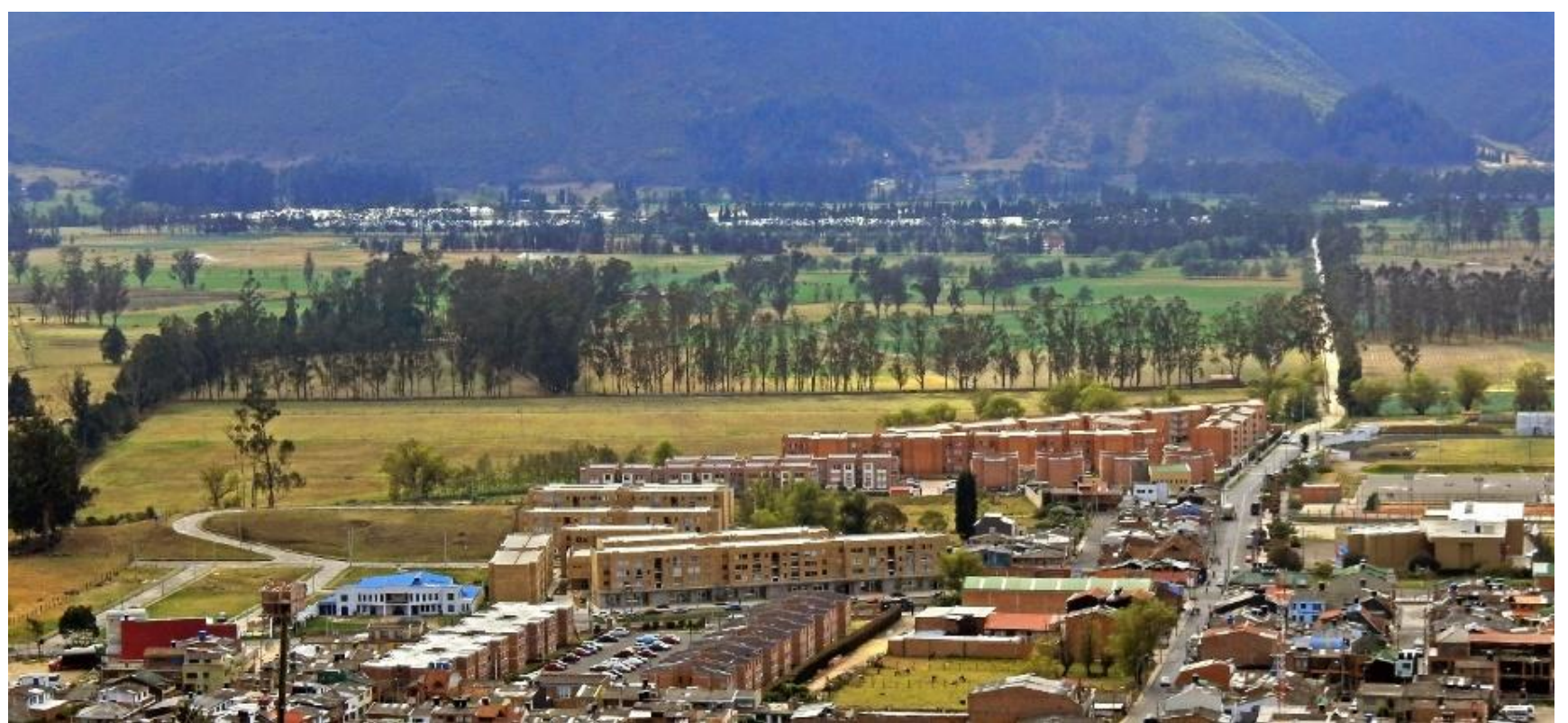

Imagen 4 Patrón urbanístico del crecimiento por agregación. Agrupación de vivienda multifamiliar en Sopó. Fuente: Imagen del autor 


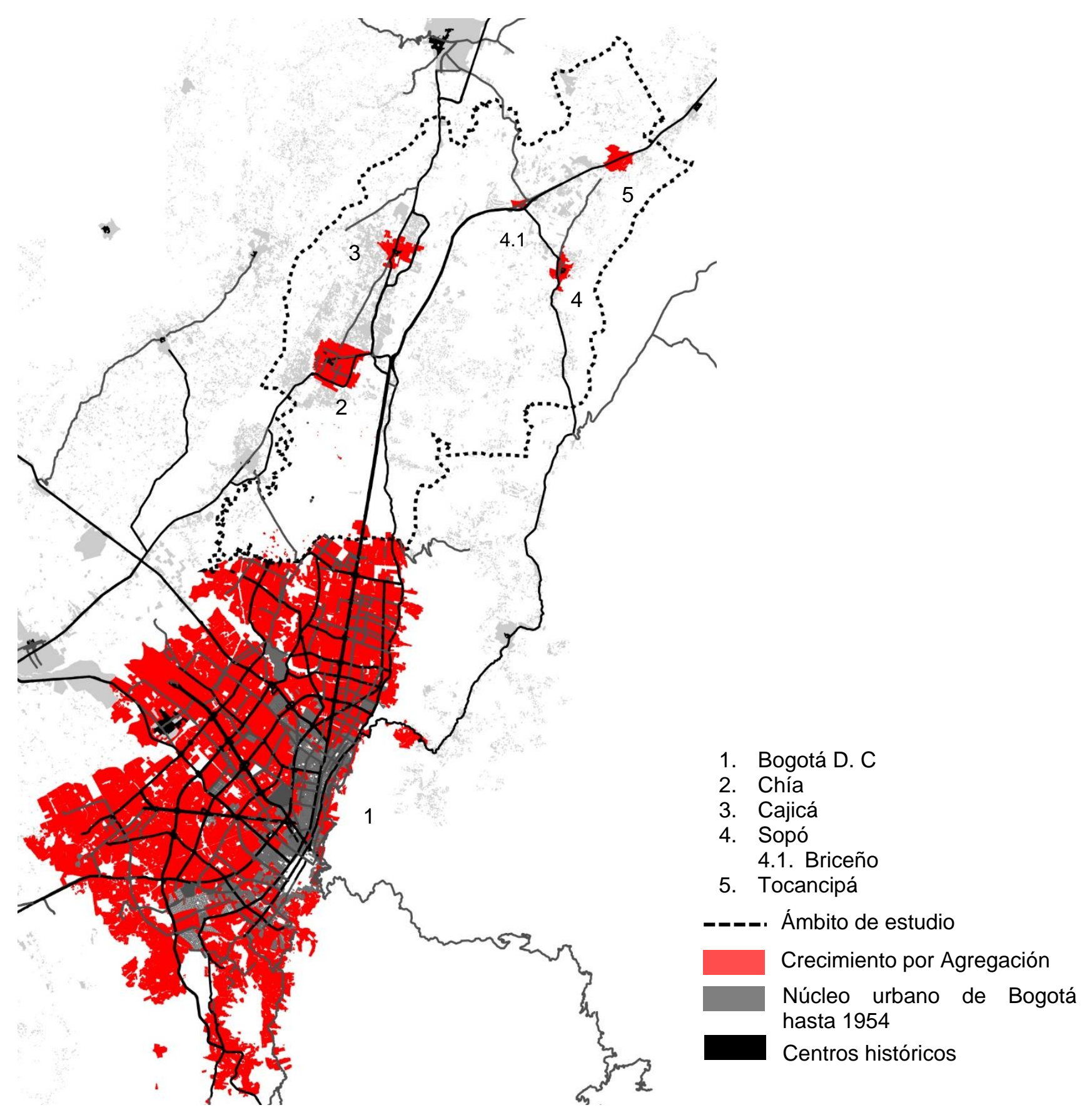

Imagen 5 Modelo de crecimiento metropolitano por agregación. Fuente: elaboración propia con base en datos del IGAC, UECD, POT Chía, POT Cajicá, (Calderon, 2016), Google Earth.

\subsection{Crecimiento por agregación}

La agregación de tejidos urbanos con cierta mixtura de usos, ya sea por la extensión de la trama urbana o por la agregación de piezas residenciales, educativas, industriales etc. de planificación unitaria a los núcleos urbanos de la ciudad central y de los municipios metropolitanos, es la principal característica de este modelo de crecimiento metropolitano. (Font Arellano, Llop, \& Vilanova, 1999)

Tradicionalmente el crecimiento urbano se concentraba en los núcleos y, en la región metropolitana, el núcleo de Bogotá concentraba la mayor parte. Excepto los cascos urbanos de Facatativá, Zipaquirá, Fontibón, Funza, 
Mosquera, Madrid y Chía que tenían una dinámica de crecimiento urbano importante, los cascos del resto de los municipios de la Sabana de Bogotá no tuvieron una expansión notoria, sino hasta la década de los años setenta y en algunos casos los ochenta. El casco urbano estaba reducido al histórico de las nueve manzanas de fundación española.

Ya para los años cuarenta la expansión de Bogotá supera, en algunos casos, el término municipal de la capital y crece en los límites municipales dentro de los términos de los municipios contiguos (Fontibón, Engativá y Bosa). El crecimiento de Bogotá desde aquel tiempo se caracterizaba por la expansión del núcleo urbano, y su materialización no era el de una agregación continua de la estructura urbana a manera de un ensanche planificado, sino la yuxtaposición discontinua de barrios residenciales conectados al núcleo por la extensión de vías y caminos desde el núcleo central, así como de la agregación de piezas de planificación unitaria, como campuses universitarios, militares, clubes campestres, etc. Este tipo de crecimiento dejaba espacios intersticiales rurales que luego el crecimiento de la ciudad se ha ido encargando de rellenar, configurando tejidos continuos y mixtos. Esta lógica de crecimiento tuvo un ritmo acelerado hasta los años ochenta, momento desde el que ha dismiuido progresivamente.

Desde principio de siglo, a causa de la reducción del suelo urbanizable en Bogotá y un crecimiento urbano más planificado e industrializado, la construcción de la ciudad por pequeñas urbanizaciones residenciales conectadas por la extensión de trazados es una característica del crecimiento informal, activo actualmente, pero con una intensidad mucho menor que en el pasado. (El crecimiento informal intenso se ha trasladado a otros municipios de la Sabana de Bogotá y está presente también en los municipios estudiados en este trabajo, pero materializado de forma diferente a como se ha presentado en Bogotá.)

La región ha crecido históricamente bajo el modelo por agregación. El surgimiento de otros modelos de crecimiento metropolitano a partir de los años setenta no significa que esta lógica de expansión de los núcleos haya desaparecido o disminuido en su intensidad, sino que otros modelos de crecimiento, a una escala metropolitana, contribuyen a que la urbanización se presente con una variedad inédita hasta hace treinta años en la región metropolitana de la Sabana de Bogotá.

Los patrones urbanísticos con los que se materializa la expansión de los núcleos urbanos municipales también se han transformado. La morfología del crecimiento se ha hecho más diversa y, además de los tejidos amanzanados de casas entre medianeras, desde los años ochenta las agrupaciones de viviendas en hilera de gestión cerrada fueron un patrón de agregación a los núcleos urbanos. En la última década, cuando la actividad edificatoria se ha formalizado e industrializado y dada la presión demográfica y la especulación inmobiliaria, piezas residenciales de alta densidad con tipologías de bloque y torres se han implantado por agregación en los núcleos de Chía, Cajicá y Sopó. En Tocancipá este patrón se implanta también fuera del núcleo.

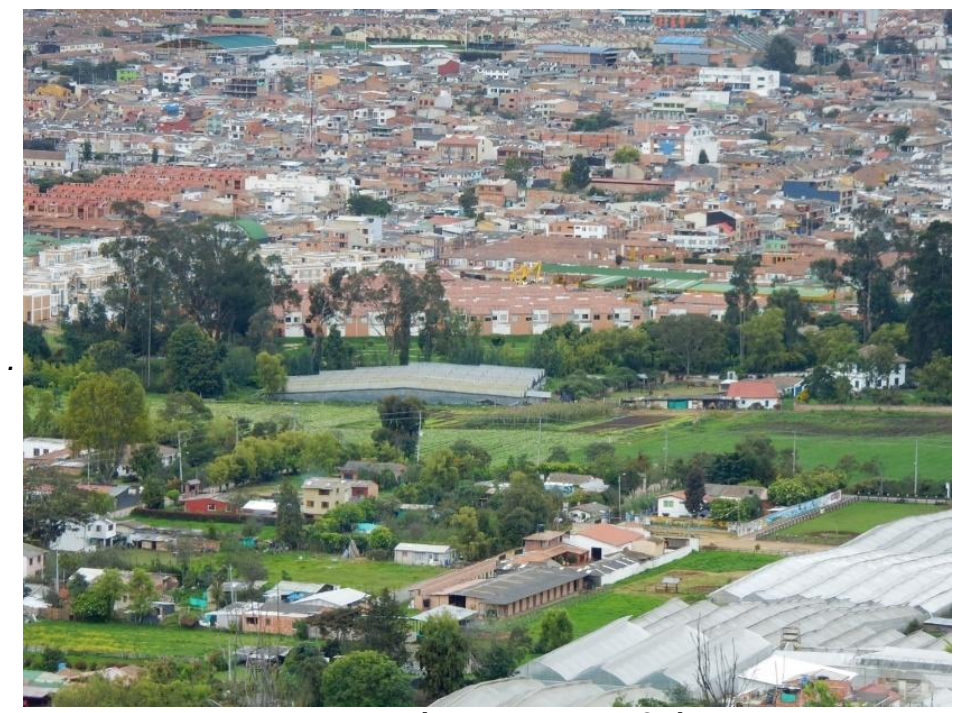

Imagen 6 Imagen 7 Borde del núcleo urbano de Chía. Fuente: Imagen del autor 


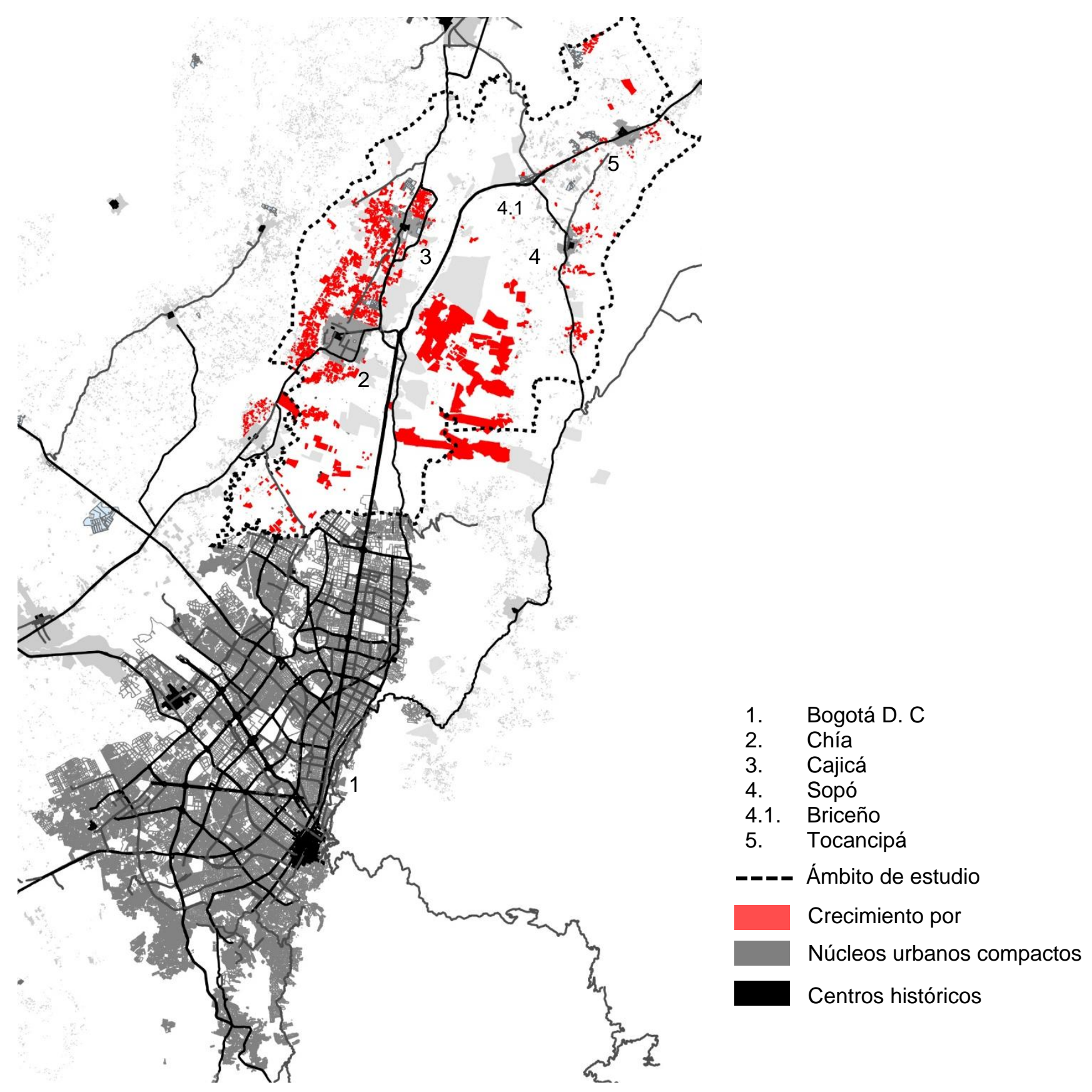

Imagen 8 Modelo de Crecimiento metropolitano por Dispersión. Fuente: elaboración propia con base en datos del IGAC, UECD, POT Chía, POT Cajicá, (Calderon, 2016), Google Earth.

\subsection{Crecimiento por dispersión}

La dispersión de la urbanización en la Sabana de Bogotá se ha expresado mayoritariamente por la implantación de diferentes patrones residenciales de baja densidad edificados con casas unifamiliares aisladas, pareadas y en hilera, tanto en las áreas de planicie como de montaña (allí solo se localizan patrones de viviendas aisladas). Los municipios en donde el fenómeno ha sido más intenso son Chía, Cajicá y más recientemente Sopó, y en mucha menor medida Tocancipá, que no concentra significativamente patrones de vivienda dispersa.

Los fenómenos de dispersión de la residencia tienen inicio en la década de los años setenta (Alfonso, 2012) pero con una intensidad aún muy baja, casi que imperceptible en el territorio. Chía y Cajicá fueron los primeros 
municipios en donde se implantaron casas aisladas para familias de altos ingresos dentro de parcelas en áreas rurales pero ocupadas en gran medida con edificaciones de actividades rurales y campesinas.

Después de la primera polarización de los años sesenta y setenta, el proceso de dispersión de la urbanización residencial o suburbanización (como este proceso es llamado localmente) es el tercer gran salto metropolitano de Bogotá hacia la Sabana.

La característica fundamental del crecimiento por dispersión es que la implantación de piezas tanto residenciales, en menor medida industriales y de equipamientos (sobre todo colegios) es exenta de los núcleos urbanos tradicionales e inclusive de la red de vías principales de conexión regional y nacional. Es un proceso de desconcentración residencial mayoritariamente hacia el territorio rural desde Bogotá a los municipios más próximos.

En Chía y Cajicá se parte de un territorio fragmentado en pequeñas propiedades rurales, con una ocupación campesina considerable ya desde la década de los años treinta. ${ }^{7}$ Esto explica por qué, alrededor de los pueblos de indios, los conquistadores españoles ubicaron los resguardos indígenas en donde fueron confinados con parcelas de tierra asignadas individual y colectivamente. En Chía, Cajicá y Sopó perviven las huellas del ordenamiento territorial español, expresado en este tipo de estructura de propiedad rural.

Además de la buena conexión de Chía y Cajicá con Bogotá por medio de la Autopista Norte, la estructuración interna de Bogotá —en donde la localización de la vivienda de estratos altos y medios se produce en el norte de la ciudad - en su estructura de propiedad, tanto en tamaño de propiedad, como en su tipo de propietario, podría facilitar la progresiva ocupación de ciertas áreas: "La herencia del pasado podría tener influencia en las líneas directrices de la expansión y explicar el avance con mayor facilidad hacia el norte. Las pequeñas propiedades por su valor son bienes que pueden ser transados más fácilmente y disponibles para mayor cantidad de gente que podrían adquirirlos" (Mesclier, 2005).

Este es el soporte catastral para la ocupación suburbana de estas áreas desde los años setenta: propiedades rurales subdivididas que progresivamente han sido ocupadas por casas rurales, viviendas de origen informal y viviendas aisladas para familias de ingresos altos y medios. Recientemente el patrón de casas aisladas se ha concentrado también en agrupaciones residenciales con otras tipologías de la baja densidad como la vivienda pareada y/o en hilera.

El fenómeno se ha intensificado progresivamente, para $1978^{8}$ la ocupación del territorio tiene una condición rural en su mayoría, pero en la década de los años ochenta adquiere mayor intensidad. En el período de 1975 a 1991 se han identificado 177.9 hectáreas de suelo destinado a este tipo de vivienda. En 1980 se inicia el proceso de urbanización de la parcelación Altos de Yerbabuena, una de las primeras iniciativas empresariales de desarrollo inmobiliario que comercializaban lotes para la edificación de viviendas por encargo en los cerros de Chía, en un área forestal con un gran atractivo escénico y paisajístico.

Para el período de 1992 a 2002 el proceso de dispersión residencial aumenta la intensidad, con nuevo suelo destinado a tal uso, pero también el relleno de parcelaciones y/o condominios que tenían lotes sin edificar pero que habían iniciado el proceso de urbanización anteriormente. En este período se identificaron unas 436.5 hectáreas, es decir, el consumo promedio de unas 43.6 hectáreas de suelo por año.

Es en el último período de análisis, del año 2003 al 2016, en donde la dispersión residencial alcanza la máxima intensidad contabilizada en consumo de suelo. Alrededor de 1026.4 hectáreas fueron destinadas para el patrón residencial de casas aisladas en los términos de todos los municipios estudiados y no solamente en Chía y Cajicá. La dispersión de la vivienda campestre se ha vuelto especialmente intensa en el municipio de Sopó sobre las áreas de ladera del Valle del Rio Teusacá. El crecimiento se puede promediar temporalmente en alrededor de 102.6 hectáreas por año. Ese incremento podría explicarse por el mejoramiento vial iniciado desde mitades de la

\footnotetext{
${ }^{7}$ IGAC Aerofotografías Vuelo 45 de 1936

8 IGAC Aerofotografías Vuelo C 1797 de 1978
} 
década de los noventa, la progresiva colmatación del núcleo urbano de Bogotá y un mejoramiento de las condiciones económicas del país desde principios del siglo XXI.

En los procesos de expansión urbana residencial de Chía y Cajicá en la década de los años ochenta y noventa, los patrones urbanísticos residenciales de agrupaciones de vivienda aún no se dispersaban por el territorio, en su lugar, se implantaron en los núcleos urbanos (con mayor notoriedad en Chía) con tipologías de casas en hilera en su gran mayoría y fueron en parte la materialización de la expansión por agregación de piezas de los núcleos urbanos. La dispersión de las agrupaciones de vivienda (conjuntos cerrados como se conocen en Bogotá) se ha reconocido según la foto interpretación de las imágenes aéreas históricas a partir de principios del siglo XXI.

El crecimiento disperso residencial es uno de los de mayor consumo de suelo suburbano y rural, con 1.637 hectáreas desde los años setenta hasta la actualidad. ${ }^{9}$

Después de la dispersión residencial, la dispersión de equipamientos educativos — sobre todo en el territorio rural del norte de Bogotá- es la más notoria. Colegios privados para estudiantes provenientes de Bogotá, con el atractivo de contar con espacios verdes e instalaciones deportivas. Ha sido un proceso desde los años setenta hasta la actualidad y que, al igual del proceso residencial, en el sector norte de Bogotá la implantación de este tipo de instalaciones ha disminuido en intensidad.

En este modelo se incluye la urbanización resultado de la progresiva ocupación de pequeñas propiedades rurales debido a la subdivisión de los predios, y tiene un origen informal tanto en la división de la propiedad como en el proceso de autoconstrucción y mejoramiento de las viviendas. Con el paso del tiempo, este crecimiento configura asentamientos densos con cierta diversidad de usos que se implantan como fragmentos en suelo rural sin solución de continuidad ni contigüidad con los núcleos urbanos existentes.

Este sería el ejemplo intermedio entre el de la dispersión y la agregación ya que, aunque su materialidad es morfológica y tipológicamente la de la ciudad informal tradicional (fragmentos de manzaneos y tejidos suburbanos ocupados por viviendas entre medianeras de uno, dos y tres pisos) no es así su localización con respecto a la estructura espacial de los núcleos urbanos ni la infraestructura vial. Los fragmentos se dispersan por el territorio, de Chía y Cajicá mayoritariamente, alrededor de los núcleos de estos municipios en donde encuentra una corona de pequeñas propiedades rurales que está en un rápido proceso de ocupación. Al parecer, esta estructura de pequeñas parcelas campesinas corresponde a los antiguos resguardos indígenas que los españoles localizaron fuera de los centros fundacionales de ciertos pueblos de indios. (Calderon, 2016)

El desarrollo informal progresivamente va consolidando un tipo de ocupación de carácter urbano, denso y con cierta mezcla de usos que remiten a imágenes de barrios con el mismo origen en Bogotá. y que se localiza por fragmentos en el territorio

\footnotetext{
${ }^{9}$ Cálculos propios hechos con base en datos del IGAC, POT Chía y Cajicá, UECD. No contabiliza las áreas de los grandes condominios campestres que están clasificados como patrones que crecen por polarización a lo largo de infraestructuras y ríos. No incluye las áreas dispersas de origen informal.
} 


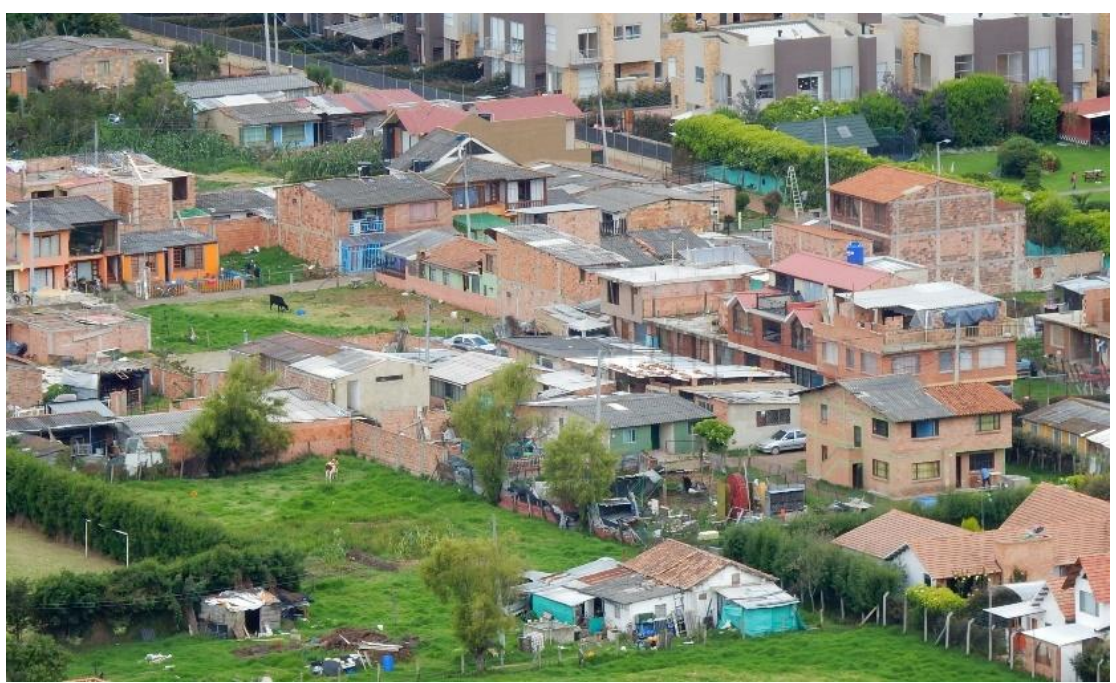

Imagen 9 Tejido suburbano espontaneo. Crecimiento disperso. Fuente: Imagen del autor

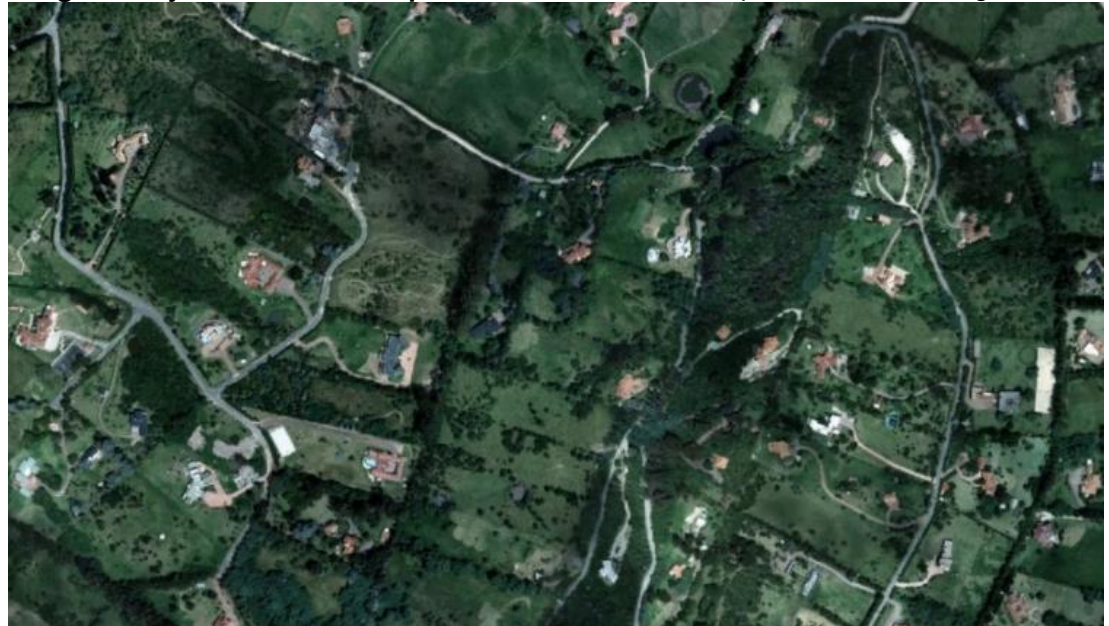

Imagen 10 Patrón urbanístico de la dispersión. Parcelación Altos de Yerbabuena en Chía. Fuente: Google Earth

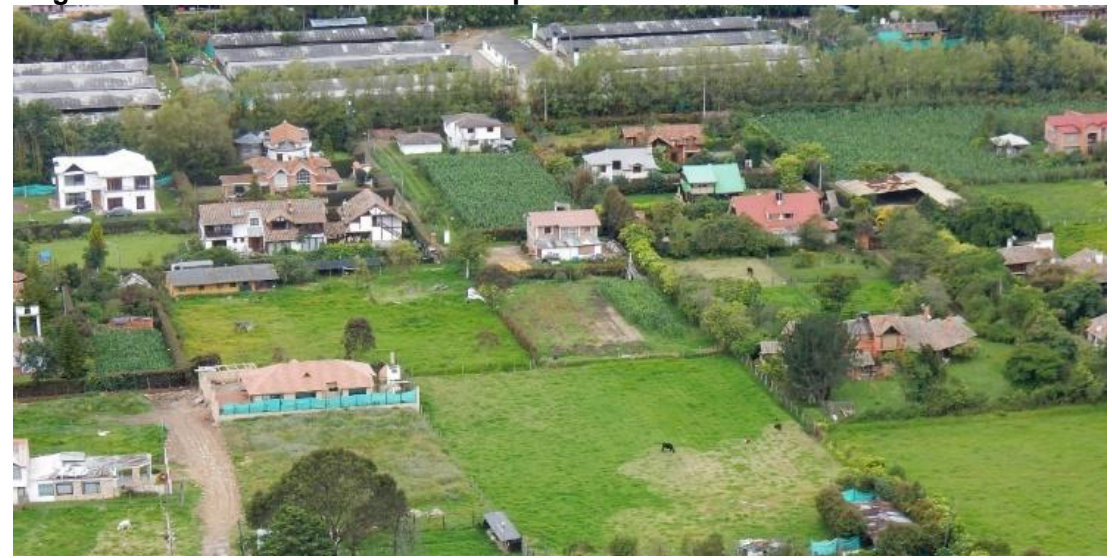

Imagen 11 Patrón urbanístico del crecimiento por dispersión, áreas de viviendas dispersas y espacios agrícolas. Fuente: Imagen del autor. 

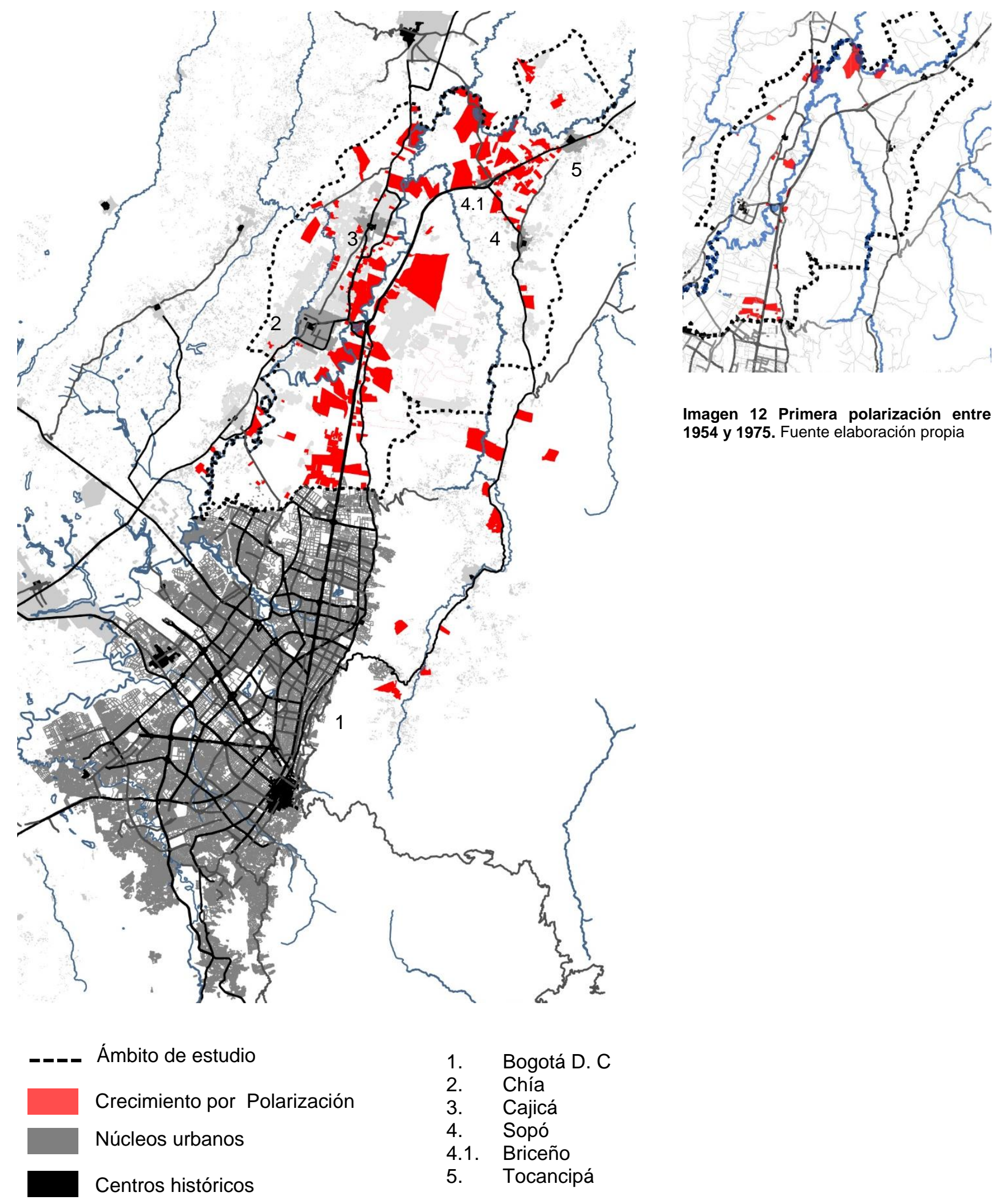

Imagen 12 Primera polarización entre 1954 y 1975. Fuente elaboración propia

Imagen 13 Modelo de crecimiento metropolitano por polarización. Fuente: elaboración propia con base en datos del IGAC, UECD, POT Chía, POT Cajicá, (Calderon, 2016), Google Earth. 


\subsection{Crecimiento por polarización}

La extensión de actividades urbanas hacia el territorio de la Sabana se materializa en la implantación de piezas de áreas considerables, generalmente de planificación unitaria y de nueva urbanización, sobre las vías de comunicación y nudos viales en busca de la mayor accesibilidad y, en algunos casos, la máxima exposición al tránsito rodado (Vecslir, 2005). Otro elemento de polarización de la urbanización son las fuentes de agua, y los ríos especialmente, que atraen instalaciones industriales, metabólicas, espacios del ocio y algunos patrones residenciales con instalaciones deportivas.

La polarización del crecimiento metropolitano se materializa en dos momentos, el del inicio y el de la explosión (últimos treinta años) del proceso de metropolización. La primera polarización la identificamos desde finales de los años cincuenta e inicio de los años sesenta con la implantación sobre el río Bogotá de instalaciones del metabolismo metropolitano como la Termoeléctrica Martín del Corral (1960), la planta de Tratamiento de agua de Tibitoc (1960) en Tocancipá junto con el club campestre de golf el Rincón en Cajicá, que se funda hacia 1958. También se implantan sobre las principales vías de conexión regional y nacional instalaciones industriales como las factorías del complejo industrial Betania $(1956)^{10}$ sobre la ruta nacional $45 \mathrm{~A}$ y Almaviva en la Caro. La fotointerpretación de las aerofotografías entre los años de 1936 y 1960 dan cuenta de la aparición de edificaciones con actividades educativas de carácter religioso, seminarios y colegios sobre las vías que conectan a Chía y a Cajicá y en La Caro y el Hospital San Juan de Dios en la vía de acceso a Chía.

En el sector rural del norte de Bogotá, el proceso de ocupación se inicia con la construcción del aeropuerto de Guaymaral a finales de los años cincuenta. Sin embargo, es desde mediados de la década de los sesenta que se detona el proceso de polarización de actividades mediante la implantación de diferentes patrones urbanísticos especializados del ocio y del metabolismo metropolitano de Bogotá. En 1965 se inicia la construcción del Club Campestre El Rancho y el parque cementerio Jardines La Inmaculada. Luego otros cementerios del mismo tipo fueron implantándose yuxtapuestos: en 1967 Jardines del Recuerdo y a principios de los años setenta Jardines de Paz (1970), junto con diferentes patrones del ocio como el antiguo autódromo Ricardo Mejía (1971) y el Club Campestre El Rancho (1972); todos se conectaban directamente a la Autopista Norte.

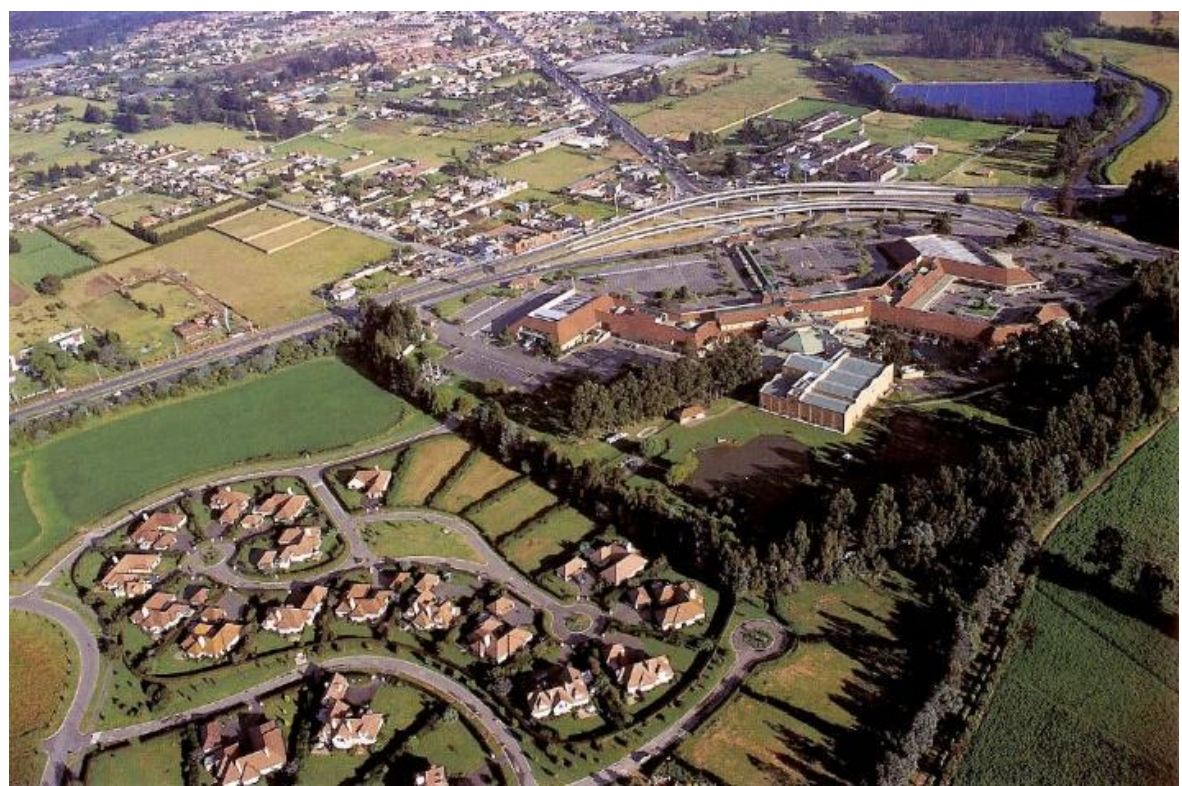

Imagen 14 Presencia de patrones de la dispersión y la polarización. Centro Chía y condominio Santa Ana de Chía. Fuente: http://www.skyscrapercity.com/showthread.php?t=538850\&page $=2$

La segunda polarización se inicia desde mediados de los años setenta con la localización, sobre la Autopista Norte, del Hipódromo de los Andes (1978). Pero es quizás un momento representativo de la "segunda

${ }^{10}$ http://www.banrepcultural.org/blaavirtual/revistas/credencial/noviembre2011/el-camino-de-la-sal 
polarización" el final de la década de los ochenta, cuando el primer centro comercial metropolitano, Centro Chía (1988), se implanta en la intersección de la ruta nacional $45 \mathrm{~A}^{11}$ con la vía de acceso a Chía. Desde este momento diferentes patrones urbanísticos residenciales, productivos, del ocio y educativos se han implantado sobre las vías vehiculares de conexión regional y nacional y sobre los ríos Bogotá, Frío y Teusacá. Este punto de la red vial es representativo por su novedad y diversidad de usos ya que, junto con La Caro, (en donde la autopista Norte se bifurca en las rutas naciones $45 \mathrm{~A}$ y $55^{12}$ ) desde finales de la década de los ochenta, se polarizaron las primeras piezas de actividades comerciales, residenciales y educativas (en 1987 inició la construcción del campus de la Universidad de la Sabana) que fueron apareciendo en las zonas rurales y o no urbanizadas de la Sabana.

La Autopista Norte en su tramo más cercano a Bogotá polariza la ocupación del suelo en sus franjas laterales con cierto ritmo continuo durante la década de los años ochenta e inicios de la de los noventa, cuando se implantan diferentes actividades comerciales (Parque Guaymaral, Multiparque y centro comercial Bima), industriales (actualmente dedicadas, en su mayoría, a actividades comerciales automotrices), de instalaciones dedicadas a la formación (Colegio Odontológico) y en menor medida agroindustriales (Invernaderos de cultivos de flores). Desde los años ochenta, en los tramos más lejanos a Bogotá sobre la Autopista Norte-Carretera Central del Norte en Cajicá y Sopó, se polarizan patrones urbanísticos del ocio como el Club Militar de Golf (19771988) y patrones que por primera vez aparecían en la región, como es el parque temático Jaime Duque (abrió sus puertas al público en 1983).

Para inicios del período de análisis que comprende del año 1991 al 2002, diferentes patrones urbanísticos se implantan en los tramos de la vía Autopista Norte-Carretera Central del Norte y la Ruta Nacional 55 independientemente de su cercanía con Bogotá. En el gobierno de Cesar Gaviria se formuló la primera generación de concesiones viales que fueron adjudicadas entre 1994 y 1997 y que mejoraron la infraestructura vial sustancialmente, ampliando las vías de una calzada a vías de doble calzada y varios carriles por sentido, así como la construcción de intercambiadores viales y variantes para evitar el paso por los cascos urbanos de los municipios. Estas obras facilitaron la movilidad intra metropolitana y facilitaron la ampliación de las actividades urbanas por el territorio.

En municipios más distantes como Tocancipá, grandes factorías como Cervecería Leona y Colpapeles se localizaron en áreas que el municipio había destinado para el uso industrial, y por primera vez se observan en la región metropolitana grandes condominios de vivienda aislada y de gestión cerrada para poblaciones de alto nivel de renta. El condominio Santa Ana de Chía empieza el proceso de parcelación, urbanización y edificación desde 1993 ocupando 59.6 hectáreas de suelo. El condominio Aposentos en Sopó, aún más distante del casco urbano de Bogotá ocupa un área de 192 hectáreas y 410 parcelas para casas aisladas e incluye un campo de golf en sus instalaciones, una configuración novedosa que hasta ese momento no se había presentado en la Sabana.

Los espacios del ocio, sobre todo clubes privados de golf, continúan implantándose sobre la Carretera Central del Norte en Sopó, como es el caso de los clubes Hato Grande Golf y Tenis Club y Britania Country Club.

Desde hace poco más de quince años, la urbanización del campo ha sido especialmente intensa. En el período comprendido entre el 2003 hasta el 2016 la polarización de actividades sobre la "horqueta vial" formada por la Autopista Norte, la Carretera Central del Norte y la vía Nacional 55 es cada vez más amplia en los usos, actividades, así como en consumo de suelo rural y suburbano. Patrones urbanísticos de las seis familias funcionales, diferenciados en diferentes subcategorías morfológicas, se encuentran sobre las infraestructuras viales.

En este período es notoria la implantación de instalaciones industriales y logísticas en el triángulo Briceño, Sopó y Tocancipá a lo largo de la autopista y sobre vías secundarias que se conectan a ellas configurando un gran emplazamiento de piezas autónomas de diferentes tipos yuxtapuestas sin soluciones de continuidad, vial ni espacial.

\footnotetext{
${ }^{11}$ Vía que conecta a Bogotá con Chía, Cajicá y Zipaquirá.

${ }^{12}$ Carretera Central del Norte
} 
En la residencia, a manera de paquetes que se enganchan a las vías principales, especialmente a lo largo de la Autopista Norte y la carrera $7^{\underline{a}}$ en Bogotá y la Ruta 55 en Chía y Cajicá, patrones de planificación unitaria, gestión cerrada, baja densidad en casas aisladas o pareadas y alto consumo de suelo son una característica a resaltar de este período.

Las actividades comerciales en grandes artefactos habían estado contenidas en los núcleos urbanos (excepto por algún ejemplo aislado como Centro Chía de 1988) especialmente en Bogotá. Es reciente la aparición de nuevos centros comerciales, grandes superficies y el anuncio de nuevos proyectos de este tipo en los municipios metropolitanos. Los grandes artefactos comerciales se implantan directamente sobre las vías de primer orden buscando tanto la máxima accesibilidad vehicular como la máxima exposición visual al consumidor. El gran comercio se ha localizado en función de Bogotá y las áreas más urbanizadas del sector norte de la Sabana. Los primeros complejos comerciales se implantaron en los años ochenta a lo largo de la Autopista Norte cercanos a Bogotá. Los más recientes artefactos comerciales como Home Center en Cajicá y el centro comercial Fontanar en Chía, ambos a lo largo de la vía 55, y Price Smart también en Chía sobre la Carretera Central del Norte han abierto sus puertas en 2016.

Es en el período de análisis más reciente en el que la polarización de actividades, artefactos, instalaciones industriales y logísticas, edificaciones de diversos tipos y viviendas a lo largo de las vías se ha dado con mayor intensidad. Los patrones de la polarización están conectados por vías propias directamente a las infraestructuras o mediante una red vial secundaria. Otra característica a resaltar de este modelo y sus correspondientes patrones urbanísticos es el alto consumo de suelo, la baja densidad y que son objeto de una planificación unitaria.

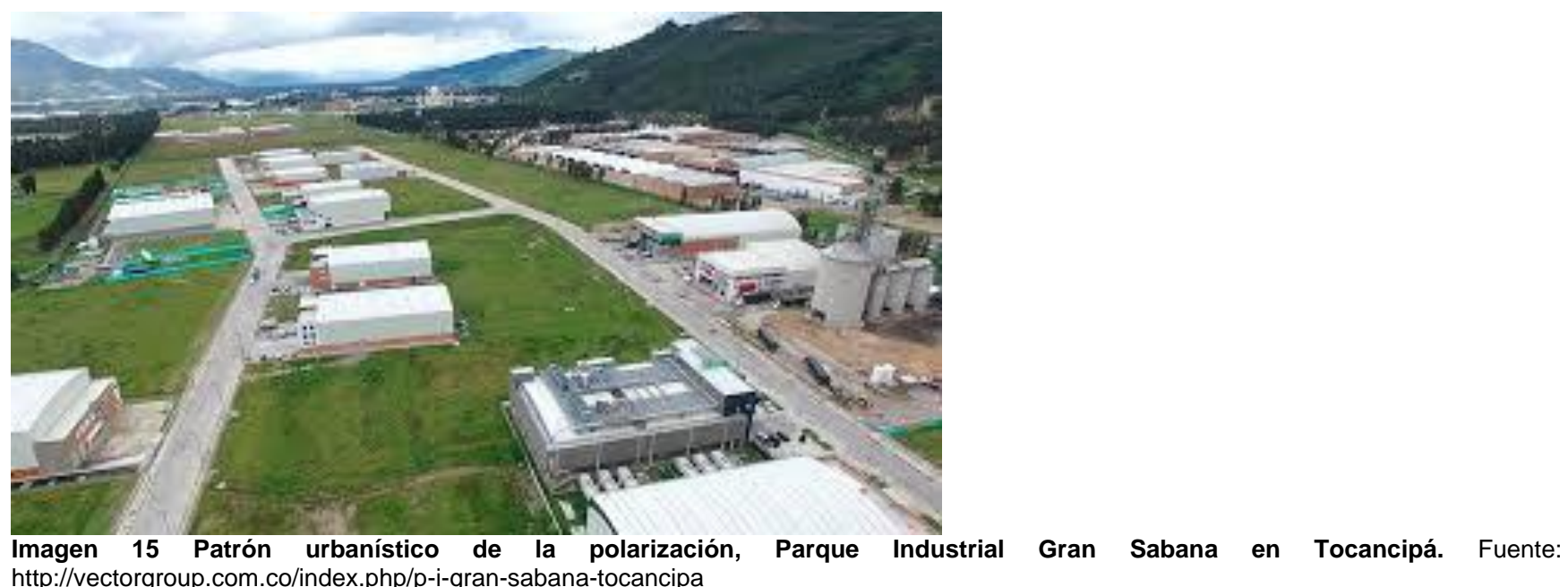




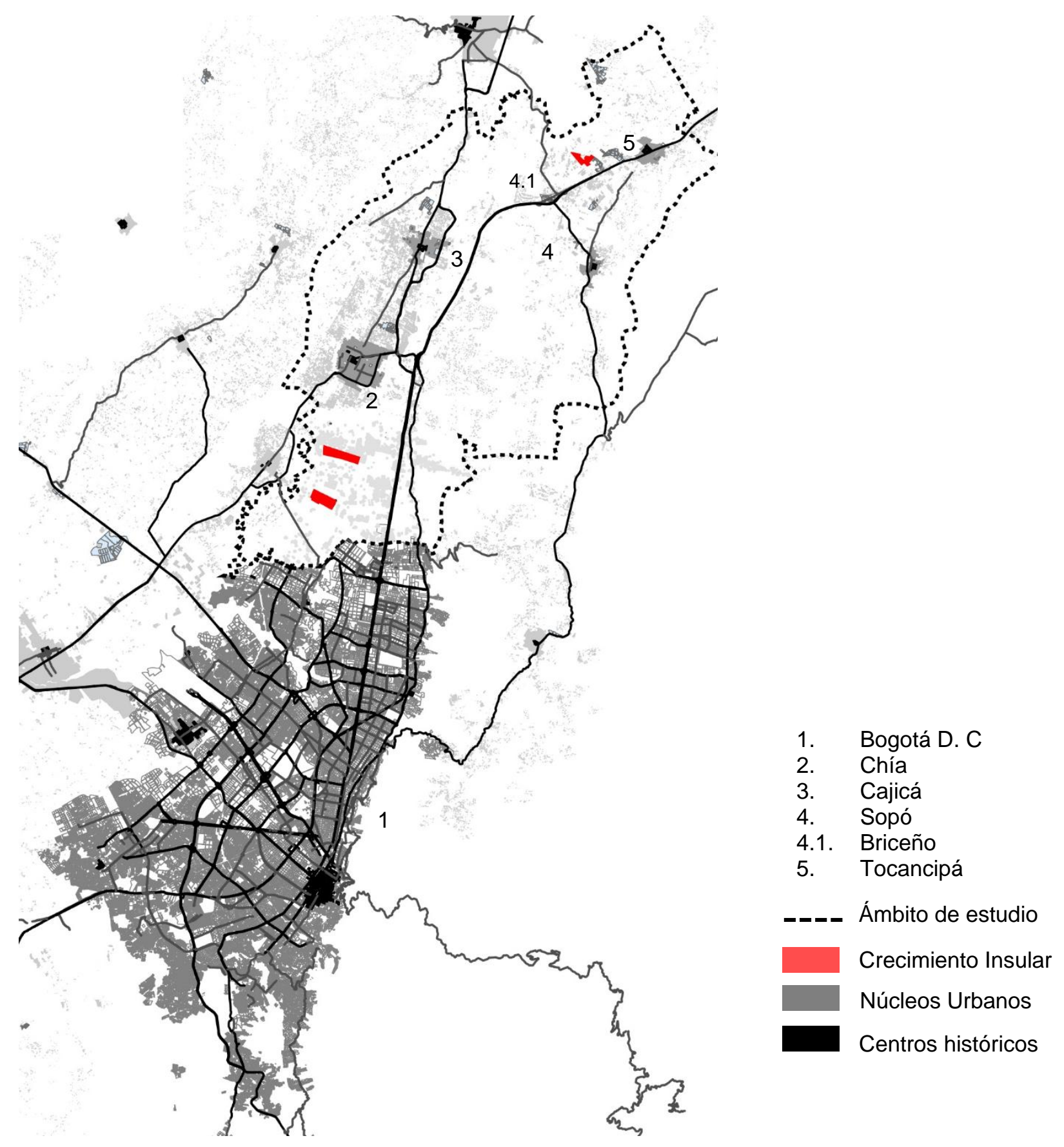

Imagen 16 Crecimiento Insular. Fuente: elaboración propia con base en datos del IGAC, UECD, POT Chía, POT Cajicá, (Calderon, 2016), Google Earth.

El crecimiento insular es una subcategoría del modelo de crecimiento por polarización y se refiere a la implantación de grandes instalaciones aisladas de planificación e intervención unitaria. En el territorio estudiado, podríamos clasificar como "crecimiento insular" al aeropuerto Guaymaral, el club campestre Los Arrayanes y el Autódromo de Tocancipá, cuya implantación inicial fue aislada tanto de los núcleos urbanos como de las infraestructuras viarias, aun cuando en el presente, por cuenta de la rápida urbanización, paulatinamente se van incorporando al gran "continuum" construido metropolitano. 


\section{Conclusiones}

Los modelos de crecimiento metropolitano no tienen una continuidad cronológica estricta, aunque sí es reconocible la aparición e intensificación de cada uno de ellos en determinados períodos de tiempo. La primera polarización del crecimiento ocurre desde finales de los años cincuenta y sesenta por medio de la implantación de instalaciones del metabolismo metropolitano y patrones urbanísticos del ocio. Luego, a finales de los años ochenta e inicios de los noventa, se inicia un nuevo proceso polarizador de actividades que se intensifica por mucho en el último período de análisis (2003-2016).

El modelo de crecimiento por dispersión no tenía antecedentes hasta finales de los años setenta y luego se intensifica hasta alcanzar el punto máximo de patrones residenciales dispersos por el territorio en los últimos quince años.

Una situación similar ocurre con el crecimiento insular informal, su aparición en el territorio coincide con la gran explosión demográfica de Bogotá y posteriormente de los municipios (década del setenta). Aunque su consumo de suelo es relativamente bajo comparado con los otros modelos, ha sido un proceso en continua intensificación en los años recientes.

La expansión de los núcleos urbanos, tanto el central como el de los municipios, es la expresión del modelo de crecimiento por agregación, el cual ha sido continuo y sin interrupción. La temporalidad entre el crecimiento de los núcleos urbanos de Bogotá y los de los municipios, en cambio, es inversa. Ahora que las áreas urbanizables dentro de Bogotá disminuyen, ha aumentado la expansión de los núcleos municipales.

Si se tiene como referencia el núcleo central, desde 1954 hasta el 2013, podría afirmarse que el modelo de crecimiento por agregación es el modelo dominante en la región metropolitana. En ese período Bogotá se expandió de $5,864^{13}$ hectáreas a $38,430^{14}$, es decir, se agregaron 32,566 hectáreas. Ningún otro modelo ha consumido tal cantidad de suelo. La preeminencia de Bogotá y la diferencia demográfica y de extensión con Soacha (que es la segunda ciudad de la región metropolitana) es muy grande ${ }^{15}$, diferencia aún mayor con los otros municipios de la región. La población combinada de los cuatro municipios del ámbito de estudio es de 253,498 habitantes ${ }^{16}$, el área urbana de Sopó es de 107 hectáreas, la de Cajicá de 307.2 hectáreas, la de Chía es de 626.9 hectáreas. y la de Tocancipá de 289.9, lo que suma una extensión total urbana de 1,331 hectáreas, que equivale al $3.46 \%$ del área de Bogotá. Sin embargo, el consumo de suelo de actividades urbanas en el período de 2003 a 2016 es similar entre el núcleo central mediante el modelo de agregación y el de los municipios estudiados combinando todos los modelos de crecimiento metropolitano. Bogotá creció en 4,321 hectáreas y los municipios en 4,230 hectáreas en total y en 3.639 hectáreas por fuera de los núcleos.

Esto nos indica que ha habido una explosión urbana importante en los últimos años con alto consumo de suelo, bajas densidades y con lógicas que se desligan de las de los núcleos urbanos municipales. Sin olvidar que este crecimiento polarizado y disperso reciente está ligado al comportamiento del núcleo de la ciudad central y son actividades urbanas pero que se implantan por fuera de los núcleos tradicionales.

El perfil morfológico de las áreas construidas de la Sabana es cada vez más diverso, está condicionado por los estratos que configuran el territorio, sin embargo, la materialización es cada vez más genérica. Está constituido por 1) patrones urbanísticos de planificación unitaria, autocontenidos polarizados en la infraestructura vial, 2) Edificaciones dispersas, 3) tejidos mixtos compactos de localización fragmentada en el territorio y 4) los núcleos urbanos tradicionales, todos ellos conectados entre sí a través de la red vial y los espacios libres.

\footnotetext{
${ }^{13} \mathrm{http}: / /$ institutodeestudiosurbanos.info/endatos/0100/0140/01412.htm

${ }^{14}$ Área del perímetro urbano

${ }^{15}$ Según proyecciones del censo de 2005 Soacha cuenta con una población de 533,718 habitantes y Bogotá de 8.080 .734 y una extensión de 2.673 hectáreas y 38.000 hectáreas respectivamente.

${ }^{16}$ Proyecciones a 2017 del Censo de 2005
} 


\section{Bibliografía}

Alcaldía Mayor de Bogotá. (2000). Monografias Territoriales Chia, región Bogotá-Sabana. Bogotá: Alcaldía Mayor de Bogotá.

- Monografias Territoriales Tocancipá, región Bogotá-Sabana. Bogotá: Alcaldía Mayor de Bogotá.

- Monografias Territoriales Sopó, región Bogotá-Sabana. Bogotá: Alcaldía Mayor de Bogotá.

- Monografias Territoriales Cajicá, región Bogotá-Sabana. Bogotá: Alcaldía Mayor de Bogotá

Alcaldía Mayor de Bogota, S. D., \& Ruiz, C. (2014). Región Metropolitana de Bogotá: una visión de la Ocupación. Bogotá: Alcaldía Mayor de Bogota.

Alexander, C. (1977). A Lenguage of Patterns. New York: Oxford University Press.

Alfonso, O. (2012). Bogotá segmentada : Reconstrucción histórico-social de la estructuración residencial de una metrópoli latinoamericana. Bogotá: Universidad Externado de Colombia.

Barco, C., \& Cortés, R. (2000). Aproximación a las directrices de ordenamiento territorial para Bogotá y la Región. Bogotá: Departamento Administrativo de Planeación Distrital.

Calderon, A. (2016). Territorios Simultaneos. Barcelona: Universidad Politecnica de Cataluña.

Cortez, M. E. (2006). La anexión de los 6 municipios vecinos a Bogotá en 1954. Bogotá: Universidad Nacional de Colombia.

Currie, L. (1984). La politica urbana en un marco macroeconómico. Bogotá: Banco Central Hipotecario.

Echeverri, J. C. (2002). Memorias de la Recesion de Fin de Siglo en Colombia: Flujos, Balances y Política Anticiclica. Bogotá: Departamento Nacional de Planeación.

Font Arellano, A. (2007). La explosión de la ciudad: transformaciones territoriales en las regiones urbanas de la europa Meridional. Barcelona: Ministerio de Vivienda.

Font Arellano, A., Llop, C., \& Vilanova, J. M. (1999). La construcció del territori metropolitá. Barcelona: Agpograf. Font, A. (2014). Los Patrones Urbanisticos. (M. Romero, Entrevistador)

Font, A. A., Vecslir, L., Maristany, Lorena, \& Mas, S. (2012). Patrons Urbanistics de les Activitats Economiques:Regió Metropolitana de Barcelona. Barcelona: Universidad Politécnica de Cataluña.

Gouset, V. (1998). Bogotá:nacimiento de una metropoli. LA marginalidad del proceso de concentración urbana. Bogotá: Tercer Mundo Editories.

Mesclier, E. (2005). Propiedad Agraria y Expansión Urbana en la Sabana de Bogotá. En V. Goueset, L. M. Cuervo, T. Lulle, \& H. Coing, Hacer Metropoli: la región urbana de Bogotá de cara al siglo XXI (págs. 291-329). Bogotá: Universidad Externado de Colombia.

Pachón , A., \& Ramirez, M. T. (2006). La Infraestructura del transporte en Colombia durante el siglo XX. Bogotá: FCE-Banco de la República.

Ruiz, C. (31 de Agosto de 2016). El proceso de urbanización en la Sabana de Bogota. (M. R. Mejía, Entrevistador)

Secchi, B. (1968). Las bases teoricas del análisis territorial. En B. Secchi, Análisis de las Estructuras Territoriales (págs. 17-94). Barcelona: Gustavo Gili.

Sieverts, T. (2003). Cities Without Cities: an interpretation of the Zwischenstadt. New York: Spon Press.

Sola-Morales, M. d. (1997). Las Formas del Crecimiento Urbano. Barcelona: Edicions UPC.

Vecslir, L. (2005). Paisajes de la nueva centralidad. Barcelona: DUOT-UPC.

Zambrano, F. (s.f.). Instituto de Estudios Urbanos. Obtenido de Breve Historia de Bogotá: http://institutodeestudiosurbanos.info/endatos/0000/resenia.htm 